ORIGINAL ARTICLE

\title{
Assessment of Parental Self-management of Epileptic Pediatric in terms of adherence of antiepileptic drugs
}

\author{
DANYAL IFTIKHAR ${ }^{1}$, RABIA FAROOQI ${ }^{2}$, SHAHZAD WAHEED QURESHI ${ }^{3}$, AMINA TARIQ ${ }^{4}$, AMNA MEHWISH IKRAM ${ }^{5}$, \\ ADEEL HAIDAR ${ }^{6}$ \\ ${ }^{1}$ Department of Pharmacy, Bahauddin Zakariya University Multan \\ ${ }^{2}$ Assistant Professor of Psychology, University of Central Punjab, Lahore \\ ${ }^{3}$ Associate Professor of Oral and Maxillofacial surgery, University College of Medicine and Dentistry, University of Lahore, \\ ${ }^{4}$ Postgraduate research coordinator, Research cell, University College of Medicine and Dentistry, University of Lahore \\ ${ }^{5}$ Assistant Professor of Science of Dental Materials, Islam Dental College, Sialkot \\ ${ }^{6}$ Assistant Professor of Oral Pathology \& oral Diagnostics, University College of Medicine and Dentistry, University of Lahore \\ Correspondence to Amna Tariq, Email id: aminatariq8@gmail.com Cell:0336-0333108
}

\begin{abstract}
Aim: To assess the parental self-management of epileptic pediatric in terms of adherence of antiepileptic drugs Methodology: A descriptive cross-sectional study was conducted in Children Complex Hospital of Multan. Convenient sampling technique was used to collect the data from included population, care giver of epilepticus children. Reliability checked by Cronbach alpha which was 0.71 . Data was analyzed in SPSS 25 , to get percentage and frequency.

Results: The majority of the responses were agree $86(81.9 \%)$ on the doctors/nurses fully explained seizures/epilepsy (diagnosis). 10(9.5\%) were strongly agree that doctors and nurses fully explained seizures to them. What side effects they have to look for while they are in treatment, was reported in positive by $73(69.5 \%)$ participants. $63(60 \%)$ were agree about whom to contact for questions or problems. The results show that the $71(67.6 \%)$ were agree about the confidence with which they can in partnership with the health care team can manage side effects if occur.
\end{abstract}

Conclusion: Parental self-management was found higher in epileptic pediatrics in Multan

Keywords: Epileptic drugs, Pediatrics, self-management, nurses

\section{INTRODUCTION}

Epilepsy can be defined as common neurological condition in which a person is prone to recurrent epileptic seizures. There are many types of epilepsies characterized by different seizure types ranging in severity and etiologies. Regulation of electrical activity in the brain resulting synchronized and excessive neuronal discharge. Patient with epilepsy may have neurodevelopment delay, cognitive impairment and may observe depression and anxiety ${ }^{1}$.

Epilepsy is the most common neurological problem among children. To improve the quality of life of the epilepticus children proper and right management is required. Children with well controlled seizures have different concerns than people with poorly or uncontrolled seizures. Children which are facing uncontrolled seizure attacks have to go through a significant illness. Such children also have to bear social stigma and society behavior towards them. It may give to mental health issues among these ${ }^{2}$.

The factors include internal also called biological factors and external. Internal ones are due to problem and structure in the brain activity but the external factors are due to the reactions of others people, or maybe it includes child own response to the fear and anxiety. Another external factor that may influence the behavior of child may be the use of certain medication to control seizure ${ }^{3}$.

Anticonvulsant medications stop the excessive electrical activity in the brain. In Children having epilepsy impulse control problems are common, most common are

Received on 05-02-2021

Accepted on 25-06-2021 aggression, frustration, socially unacceptability, anxiety. Helping a child to understand what epilepsy is can help child both empowered and it can also give him confidence too ${ }^{2}$.

Out of 100 about 65 children with newly diagnosed epilepsy can easily recover from the seizure with the medications that are recommended to them in the very start.15 to 20 children can get them seizure free with the additionally prescribed antiepileptic medications. But on an average remaining child cannot get seizure free with the available AEDs. ${ }^{4}$ The primary aim of the AEDs drug in the treatment is to provide minimum harmful or toxic effects in the body and to control seizures. But it is known that non adherence to these drugs can enhance the epilepsy seizures ${ }^{5,6}$.

So, there is a need to explore the level of selfmanagement among epileptic pediatrics that are on antiepileptic drugs. There should be such activities which help in reducing the adverse side effects, bringing back to healthy life style, good and healthy diet, and to lessen the depression, anxiety and stress are included in the selfmanagement of the epilepsy ${ }^{7,8}$.

\section{MATERIAL AND METHODS}

This study was a descriptive, cross-sectional conducted at Children Complex Hospital of Multan. The study duration was 4 months (December, 2019 to March, 2020). Data was collected using non-probability convenient sampling. Sample size calculated $n=105$. The study population was care giver or parents of in-patient children. Study was conducted after, Institutional approval from Ethical Committee Children Complex Hospital Multan. Informed 
Consent taken from the participants. Privacy and participant confidentiality were maintained throughout the study, only assess relevant components. Also informed them to withdraw from the study at any time without any penalty. Data was collected after their agreement.

Collection of data was done after inform consent taken. Data collection was performed through questionnaire with describe and explain. Data was collected at Morning twice a week (Saturday and Sunday).

Pediatric epilepsy self-management Questionnaire (PEMSQ) developed by Modi was used after taking permission from the author. PEMSQ is standardized tool with 19 validated questions. ${ }^{9}$ Tool items consisted of 2 parts, 1) Demographic data consisted 10 items, 2) Resting questioner consisted on 27 items which cove the selfmanagement and adherence to use the anti-epileptic drug in pediatric. The questionnaire reliability was checked by Cronbach alpha and which was 0.71 .

Inclusion and exclusion criteria: Patients with medication refilling and follow up evaluation were also included in the study. Patients with the age range of 1 month to 17 years were included in the study. Patients with co morbid conditions were excluded. Participants who meet the inclusion criteria were given a questionnaire consisting of participant demographic data and questionnaire. Participants were also asked to fill informed consent proforma to willingly include in our study. Data was analyzed computing statistically through SPSS version 25 . Include descriptive statistical analysis.

\section{RESULTS}

The results showed that the male participants were $41.9 \%$ and $58.1 \%$ female. Age limit of the majority participants were fall in 1 month to 5 years $51(48.6 \%)$, then 6 to 10 years $39(37.1 \%)$, and $5.7 \%$ were fall in the age of 16 to 17 years. Significant participants family history was included in the response of Yes $29(27.6 \%)$ and $76(72.4 \%)$ in No. Majority of the participants were notices that they had first seizures onset after one year $66(62.9 \%$. The seizures frequency was revealed that $53(50.5 \%)$ weekly, 30(28.6\%) monthly, and yearly $22(21 \%)$.

Results disclose that the majority of the responses were agree $86(81.9 \%)$ on the doctors/nurses fully explained seizures/epilepsy (diagnosis). 10(9.5\%) were strongly agree that doctors and nurses fully explained seizures to them. What side effects they have to look for while they are in treatment, was reported in positive by 73(69.5\%) participants. 63(60\%) were agree about whom to contact for questions or problems. The results show that the $71(67.6 \%)$ were agree about the confidence with which they can in partnership with the health care team can manage side effects if occur. Eighty percent responses were agree about the confidence with which they can achieve the seizure freedom. 63(60\%) were agree about understanding the risk of discontinuing the medication before they have been seizure free for 2 years. The health care team listen to their concerns was reported by $57.1 \%$ respondents. Health care providers are easy to contact and readily answer questions, was agreed by $57(54.3 \%)$.

The83(79\%) were agree that they take the medication as prescribed. The directed treatment response was reported by $89(84.8 \%), 63(60 \%)$ participants reported that they don't face difficulty for follow up appointments. Majority of participants responses agreed were 57(54.3\%) on that all family members were in agreement regarding their treatment plan, The $74(70 \%)$ were agree that they felt it was important to assure that they took medication on daily basis. The medication was never easy to fit their daily schedule most often was reported by $66(62 \%)$.

Table.1 Demographic variables

\begin{tabular}{|c|c|c|}
\hline Demographic variables & Frequency & \%age \\
\hline \multicolumn{3}{|l|}{ Gender } \\
\hline Male & 44 & $41.9 \%$ \\
\hline Female & 61 & $58.1 \%$ \\
\hline \multicolumn{3}{|l|}{ Age } \\
\hline 1 month to 5 years & 51 & $48.6 \%$ \\
\hline 6 to 10 years & 39 & $37.1 \%$ \\
\hline 11 to 15 years & 9 & $8.6 \%$ \\
\hline 16 to 17 years & 6 & $5.7 \%$ \\
\hline \multicolumn{3}{|l|}{ Family history } \\
\hline Yes & 29 & $27.6 \%$ \\
\hline No & 76 & $72.4 \%$ \\
\hline \multicolumn{3}{|l|}{ First Seizure Onset } \\
\hline After birth & 5 & $4.8 \%$ \\
\hline After one month & 34 & $32.4 \%$ \\
\hline After one year & 66 & $62.9 \%$ \\
\hline \multicolumn{3}{|l|}{ Seizures Frequency } \\
\hline Weekly & 53 & $50.5 \%$ \\
\hline Monthly & 30 & $28.6 \%$ \\
\hline Yearly & 22 & $21 \%$ \\
\hline
\end{tabular}

Table 2: The tool consisted on scale of (Strongly Disagree) to (Strongly Agree) for Questions 1-18 Questions 1-18 and on a scale of (Never) to (Always) for Questions 19-27

\begin{tabular}{|c|c|c|c|c|c|}
\hline Questionnaire & $\begin{array}{l}\text { Strongly } \\
\text { disagree }\end{array}$ & Disagree & $\begin{array}{c}\text { Neither agree } \\
\text { nor disagree }\end{array}$ & Agree & $\begin{array}{c}\text { Strongly } \\
\text { Agree }\end{array}$ \\
\hline The doctors/nurses fully explained seizures/ epilepsy (Diagnosis) & $4(3.8 \%)$ & $5(4.8 \%)$ & $0(0 \%)$ & $86(81.9 \%)$ & $10(9.5 \%)$ \\
\hline I understand what side effects to look for while I am in treatment & $7(6.7 \%)$ & $9(8.6 \%)$ & $10(9.5 \%)$ & $73(69.5 \%)$ & $6(5.7 \%)$ \\
\hline I know who to contact for questions or problems & $1(1 \%)$ & $9(8.6 \%)$ & $9(8.6 \%)$ & $63(60 \%)$ & $23(21.9 \%)$ \\
\hline $\begin{array}{l}\text { I am confident that I, in partnership with thehealth care team, can manage side } \\
\text { effects if they occur }\end{array}$ & $0(0 \%)$ & $7(6.7 \%)$ & $11(10.5 \%)$ & $71(67.6 \%)$ & $16(15.2 \%)$ \\
\hline I am confident that I canachieve seizure freedom & $0(0 \%)$ & $4(3.8 \%)$ & $0(0 \%)$ & $84(80 \%)$ & $17(16.2 \%)$ \\
\hline $\begin{array}{l}\text { I understand the risks of discontinuing mymedication before I has been seizure } \\
\text { free for } 2 \text { years }\end{array}$ & $3(2.9 \%)$ & $2(1.9 \%)$ & $22(21 \%)$ & $63(60 \%)$ & $15(14.3 \%)$ \\
\hline My health care team listens to my concerns & $0(0 \%)$ & $13(12.4 \%)$ & $17(16.2 \%)$ & $60(57.1 \%)$ & $15(14.3 \%)$ \\
\hline My health care providers are easy to contact andreadily answer questions & $4(3.8 \%)$ & $18(17.1 \%)$ & $18(17.1 \%)$ & $57(54.3 \%)$ & $8(7.6 \%)$ \\
\hline I take my medicine asprescribed & $3(2.9 \%)$ & $2(1.9 \%)$ & $5(4.8 \%)$ & $83(79 \%)$ & $12(11.4 \%)$ \\
\hline I have transportationavailable to my appointments & $27(21 \%)$ & $17(16.2 \%)$ & $10(9.5 \%)$ & $45(42.9 \%)$ & $11(10.5 \%)$ \\
\hline I usually follow themedical advice and treatmentplans prescribed for me & $1(1 \%)$ & $6(5.7 \%)$ & $0(0 \%)$ & $79(75.2 \%)$ & $19(18.1 \%)$ \\
\hline I feel it is important for me to receive my treatment as directed & $1(1 \%)$ & $0(0 \%)$ & $0(0 \%)$ & $89(84.8 \%)$ & $15(14.3 \%)$ \\
\hline I have no difficultyattending my follow up appointments & $4(3.8 \%)$ & $16(15.2 \%)$ & $11(10.5 \%)$ & $63(60 \%)$ & $11(10.5 \%)$ \\
\hline
\end{tabular}




\begin{tabular}{|c|c|c|c|c|c|}
\hline All family members are in agreement regardingmy treatment plan & $4(3.8 \%)$ & $4(3.8 \%)$ & $2(1.9 \%)$ & $57(54.3 \%)$ & $38(36.2 \%)$ \\
\hline$I$ receive my medicationmost of the time & $4(3.8 \%)$ & $2(1.9 \%)$ & $4(3.8 \%)$ & $86(81.9 \%)$ & $9(8.6 \%)$ \\
\hline I feel it is important to assure that I am taking my medication on a daily basis & $4(3.8 \%)$ & $5(4.8 \%)$ & $2(1.9 \%)$ & $74(70.5 \%)$ & $20(19 \%)$ \\
\hline Medication treatment is necessary for my medical condition & $2(1.9 \%)$ & $2(1.9 \%)$ & $0(0 \%)$ & $90(85.7 \%)$ & $11(10.5 \%)$ \\
\hline The medication chosen will control my seizures & $0(0 \%)$ & $8(7.6 \%)$ & $2(1.9 \%)$ & $83(79 \%)$ & $12(11.4 \%)$ \\
\hline & Never & Seldom & Sometimes & Often & Always \\
\hline The medications are easy to fit into my daily schedule & $5(4.8 \%)$ & $2(1.9 \%)$ & $20(19 \%)$ & $66(62.9 \%)$ & $12(11.4 \%)$ \\
\hline
\end{tabular}

\section{DISCUSSION}

The study is about the self-management and adherence to the use of antiepileptic drugs in anti- epileptic pediatrics. Different adherence levels were identified during the study which was high adherence, moderate non-adherence, variable non-adherence and early non-adherence ${ }^{10}$.

Banerjee et al $^{11}$ observed more cases of epilepsy in early childhood. Our study shows that pediatrics who were given all the AEDs given at the same time were more adherent. Probability of non-adherence was likely to be increased if the care giver employed immediately. Nazziwa et al found that if the care giver was doing any job ${ }^{12}$.

There is a limitation in our study as it is a single centered study with the focus on epilepsy. The current study showed that more satisfactory results were greater in medication adherent pediatrics. Patient on one drug shows more satisfactory results in the convenience and effectiveness domains as compared with patient on more than one drug. Patient on monotherapy find it effective as they are easy to take single medication. Sweileh et al also reported that satisfactory results will be obtained when there is monotherapy treatment ${ }^{13}$.

Defined model for self-management interventions are the need of the time to create the special interest for managing the epilepsy ${ }^{14}$. Significant barriers in providing effective care include the major reality that in most hospitals there is a limited time for one patient. As there is more number of patients that's why specialists or doctors don't have much time to fully understand the patient and there financial conditions and other challenges or maybe they are not well trained to provide best care to the patient .These are the some barriers which act as a hurdle in providing best management and effectiveness to the patient ${ }^{15,16}$.

Parental scores were higher in all the four domains in the educated parents as compared to the ones which did not have a basic or structured education. This shows the importance of basic education and also shows the importance of education and awareness required epilepsy management in caregivers. The importance and requirement of documentation is also told to the parents. Printed handouts and educational seminars can also prove very helpful regarding awareness to the parents and general public.

\section{REFERENCES}

1. Kerr Mp, Mensah S, Besag F, et al. International consensus clinical practice statements for the treatment of neuropsychiatric conditions associated with epilepsy. Epilepsia 2011;52'2133-2138

2. Morita DA, Glauser TA, Modi AC. Development and validation of Pediatric epilpesy side effects Questionaire , Neurolgy, 2012 sep $18 ; 79(12): 1252-8$

3. Naik $\mathrm{N}$ expert committee on pediatric Epilepsy, indian academy of pediatrics, Guidelines for Feb 4;291 (5):615-20

4. Modi A C, Pai Al, Hommel KA ,Hood KK, cortina S, Hilliard ME, Guilfoyle SM, Gray WN, Drotar D. Pediatric selfmanagement; A frame work for reseach, practice, policy. Pediatrics.2012.feb;129(2):e473-85

5. Modi A C,Wu YP, Rausch, JR, Peugh JL, Glauser TA. Antiepileptic Drug Non -adherence predicts pediatric Epilepsy Seizure outcomes, neurology .2014, 29 : 10.1212/WNL.0000000000001-023

6. Anej SI ,Sharma S,newer antiepileptic drugs, Indian pediatr,2013 Now 8;50 (11) 1033-40

7. Modi AC, Rausch JR, Glausern TA. Patterns of non-adherence to Antiepileptic Drug therapy in children with newly diagnosed epilpesy. JAMA 2011 April 27;305(16): 1669-1676.

8. Al-Aqueel S, AISabhan J. Strategies for improving adherence to antiepileptic drug treatment in patients with epilepsy .Cochrane Database syst Rev .2011 Jan 19;1

9. Modi AC, Monahan S, Daniels D, Glauser TA. Development and validation of the pediatric epilepsy medication self-management questionnaire. Epilepsy \& Behavior. 2010 May 1;18(1- 2):94-9.

10. Nyinawumuntu J, Sebera Fm, Patel A, Hahirwa I. Adherence to antiepileptic treatment and its predictors among adolescents with epilepsy at Ndera neuropsychiatric Hospital, Rwanda (Doctoral dissertation).

11. Mani KS, Rangan G, Srinivas HV, Kalyana sundaram S, Narendran S, Reddy AK. The Yelandur study: A community based approach to epilepsy in rural South India--epidemiological aspects. Seizure 1998; 7:281-8

12. Banerjee TK, Hazra A, Biswas A, Ray J, Roy T, Raut DK, et al. Neurological disorders in children and adolescents. Indian Journal of Pediatrics 2009; 76:139-46.

13. Nazziwa R, Mwesige AK, Obua C, Ssenkusu JM, Mworozi E. Adherence to antiepileptic drugs among children attending a tertiary health unit in a low resource setting. Pan African Medical Journal 2014; 17:44

14. Sweileh WM, Ihbesheh MS, Jarar IS, Taha AS, Sawalha AF, Zyoud SH, et al. Self-reported medication adherence and treatment satisfaction in patients with epilepsy. Epilepsy and Behaviour 2011; 21(3):301-5.

15. Dilorio C,Bamps $Y$, Edwards A, et al .The prevention research centres, Managing epilepsy well network. Epilepsy Bahav (In this issue)

16. Thapar AK, Stott, NC, Richens A, Kerr M. Attitudes of GPs to the care of people with epilepsy. Fam Pract 1998;15 (5); 437-42. 